\title{
Diagnosane er ikkje gode nok
}

\author{
Diagnosesystema innan psykisk helse fokuserer på sjukdom og symptom i staden for å sjå heile \\ mennesket.
}

\section{FORFATTERE}

Eva Marit Svendsen

Seniorrådgiver

Nasjonalt senter for erfaringskompetanse innen psykisk helse

\section{HOVEDBUDSKAP}

Det har kome mange kritiske røyster til diagnosesystema ICD-10 og DSM-5 som nyttast innan psykisk helsevern. Hovudkritikken går ut på at dei gir seg ut for å vere vitskapleg grunna utan å vere det, og kan verke stigmatiserande og begrensande på behandlingstilboda.

Det trengst eit skifte frå fokus på sjukdom og symptom til å rette merksemda på den situasjonen pasienten lever i og erfaringane vedkomande har. Då må vi søke eit språk som inkluderer heile mennesket med såra og ressursane sine. Det nyttar ikkje å presse mennesket inn i ein diagnose eller eit manualbasert behandlingsopplegg.

Er ein diagnose heile sanninga om den lidinga eg har? Famnar ICD-10, som er den diagnostiske manualen som vert mest nytta innan psykiatrisk behandling, den røynda eg opplev og gir meg hjelp til å forstå og behandle det eg står overfor? Og er ICD-10 og DSM-5 gode nok verktøy i forskinga innan det psykiske helsefeltet? Slike spørsmål er relevante å stille, når diskusjonen om diagnosane er på dagsorden. I denne artikkelen vil eg presentere noko av den omfattande kritikken som har kome fram når det gjeld innhaldet i dei psykiatriske diagnosane og bruken av dei. Eg vil også peike på nokre av dei funksjonane kategorisering av psykiske helseutfordringar bør ha.

\section{DEFINISJON AV «DIAGNOSE»}

Omgrepet «diagnose» er opprinneleg gresk og samansett av orda «dia», som betyr «ved», og «gnosis», som omsettast til «erkjenning». Altså «ved erkjenning» skal ein finne den relevante løysinga på problemet. Diagnosen er ikkje berre ein merkelapp eller oppramsing av symptom, men skal kunne peike mot ein metode som kan nyttast i møtet med denne gitte erkjenninga. Vi menneske er laga slik at vi har behov for å kategorisere problema vi står overfor. Slik kan vi finne, systematisere og repetere dei beste måtane å løyse same type problem på.

Alle fag har sitt fagspråk, og dei psykiatriske diagnosane er berre språklege uttrykk for nokre kjente fenomen innan psykiatrien. Ved hjelp av desse uttrykka kan vi kommunisere om det vi står overfor blant kollegaer og skape gjenkjenning. Døme på dette er ord som «psykose», 
«nevrose», «personlegdomsforstyrring», «angst» og «depresjon». Men det er viktig å hugse at dei psykiatriske diagnosane ikkje er identiske med lidingane ein møter innan psykisk helsevern. Dei er heller ikkje avgrensa fenomen, og dei er ikkje sjølve røynda. Same diagnose kan romme mange ulike menneskelege opplevingar og uttrykk. Til dømes vert det sagt at det er minst 256 måtar å vere «borderline» på (1). Diagnosar kan nyttast både på hensiktsmessig og ikkje-hensiktsmessig vis.

\section{DIAGNOSESYSTEMET VÅRT VERT DEBATTERT}

I den siste tida har det vore mange kritiske røyster til dei diagnosesystema som nyttast innan psykisk helsevern. Omsettinga av bøkene til sosialantropolog og psykoterapeut James Davies og professor i klinisk psykologi Peter Kinderman synast å ha intensivert debatten om diagnosane sin plass i norsk psykisk helsevesen. Fleire innlegg i Tidsskrift for Norsk psykologforening, Tidsskrift for Den norske legeforening, og psykologar og psykiatrar som Tor Johan Ekeland, Trond Aarre, Anne Høie, Pål Kraft og Birgit Valla med fleire har viktige innspel i denne samtalen.

\section{DIAGNOSAR ER IKKJE VITSKAPELEGE}

Kritikken går både på innhaldet og (mis)bruken av diagnosane. Det vert peika på misforholdet mellom den posisjonen og funksjonen som diagnosane har blitt tillagt, og kva slags nytte dei gir for den einskilde brukar av dei psykiske helsetenestene. Ikkje minst vert grensene for kva diagnosesystemet kan bidra til i forståinga av psykiske helseutfordringar, påpeikt. Fleire har vore kritiske til korleis dei vert nytta i klinikken og i forskinga, men også til kva slags funksjon dei har fått i samfunnet elles (2).

Hovudkritikken til dei psykiatriske diagnosane er at dei gir seg ut for å vere basert på eit vitskapeleg grunnlag utan å vere det. Her er professor Tor-Johan Ekeland (3) krystallklar i sin kritikk. Han meiner at diagnosane skal vere vitskapeleg grunna dersom dei skal halde mål. Noko dei ikkje gjer, ifylgje han. Diagnosane bør kunne beskrive fenomenet, avgrense symptombiletet, klargjere kva slags symptom som passar saman (nosografi), få fram kva som er årsaka til lidinga (etiologi), forklare sjukdomsmekanismane (patologi), kunne vise kva slag prognose (utvikling) lidinga vil få, og kva slag behandling og tiltak som verkar (terapi). Dersom diagnosesystemet manglar ein eller fleire av desse komponentane, er det stor fare for at validiteten og reliabiliteten vert lave, og at diagnosane ikkje er haldbare og gagnbare.

\section{SAME SYMPTOMMØNSTER, MEN ULIKE DIAGNOSAR}

Korkje ICD-10 eller DSM-4 har klart å leve opp til desse krava trass i omfattande forsking. Sjansane for at fleire personar med same symptommønster skal få same diagnose, altså høg reliabilitet, har ikkje vore god nok. Likevel har standardiserte utgreiingar og intervjuguidar vore med på å høgne reliabiliteten dei siste åra. Når det gjeld kva som er årsaka til symptoma, og kva slags behandling som kan vere hensiktsmessig, har dei psykiatriske diagnosane lav validitet. Mange er tautologiske - det vil seie sirkelargumenterande: Han høyrer stemmer fordi han er psykotisk fordi han er schizofren. Han er schizofren fordi han er psykotisk og høyrer stemmer. Dei seier altså ingenting om årsaka til symptoma.

\section{«Jeg fikk bare beskjed om å spise pillene han skreiv ut.»

$$
\text { «Ingunn, } 24 \text { år» }
$$

Kritikken gjeld også det faktum at psykiatrisk forsking tek utgangspunkt i sjukdomskategoriar basert på kliniske manifestasjonar av symptom og teikn. Dette trass i at det ikkje er funne nokre biologiske markørar for dei ulike psykiatriske lidingane. ICD og DSM er diagnosesystem som begge er forankra i eit biomedisinsk paradigme. Ved å sette ein diagnose, vert såleis vår forståing av eit menneske si liding forankra i ein teori om sjukdom. Skiljet mellom det som er 
ein normal reaksjon på ein unormal situasjon og det som er ei psykisk liding, vert ikkje tydeleg i denne forståinga. Diagnosen blir som ein stereotypi og seier lite om pasienten som person og kva dette spesielle mennesket treng i vedkomande sin unike situasjon. Diagnosen kan vere rett på gruppenivå, men ikkje på individnivå.

\section{DIAGNOSEKATEGORIAR HINDRAR FORSTÅING}

I ein kronikk viser professor Anne Høye (4) ved Universitetet i Troms $\varnothing$ til den amerikanske psykiateren Steven Hyman med fleire, som representerer forskarar med eit nevrobiologisk sjukdomsperspektiv, og som er kritiske til diagnosesystema. Dei hevdar at svakheita med forsking innan psykisk helse er at ein går seg vill i det å beskrive kva som er sams og forskjellig med dei ulike lidingane. Ein får problem med å avgrense ein tilstand mot ein annan, og med å definere trekk ved fastsette diagnosar.

Det er ein aukande frustrasjon over at den nye kunnskapen vi har fått innan genetikk, nevrofysiologi, nevropsykologiske mekanismar og språkutvikling, i liten grad manifesterer seg i ny viten om årsakstilhøve, sjukdomsforløp og behandling. Dei hevdar også at dei eksisterande diagnosekategoriane hindrar ein i meir omfattande forståing. Etter det eg forstår, prøver det nye diagnosesystemet The Research Domain Criteria (RDoC) å imøtekome noko av denne kritikken.

\section{DIAGNOSANE ER FOR SNEVRE}

Ifylgje Svend Brinkmann med fleire lever vi i ein diagnostisk kultur som karakteriserast av eit psykiatrisk blikk på menneskeleg liding og avvik, der andre forståingar vert sett til side (5). Ein psykose vert til dømes tolka inn i ein (vestleg) kulturell kontekst, noko som hindrar oss i å vere opne for ei anna forståing av hallusinasjonane. Inntrykket av objektivitet, og at den er vitskapleg, kan skjule at det eigentleg er snakk om normative vurderingar.

Diagnosane fokuserer for snevert når symptoma og problema til pasienten åleine er $\mathrm{i}$ sentrum. Til dømes seier diagnosane lite om familiesamspel, korleis foreldra fungerer og korleis foreldra er som omsorgspersonar dersom mor eller far har psykiske helseutfordringar. Dei seier heller ikkje noko om korleis dei ulike tilhøva i familien, eigenskapar ved borna eller ressursar i deira sosiale nettverk og samfunnet elles verkar inn på borna sine opplevingar og mestring av mor eller far sine vanskar.

\section{LIVSUTFORDRINGAR GJERAST TIL SJUKDOM}

Kinderman meiner at psykologane har vore med og støtta opp under utviklinga mot ei stadig større patologisering av vanlege livsutfordringar (6). Han meiner at psykologane skal slutte å stille diagnosar og heller skildre problema til klientane på ein normal, attkjenneleg måte. Det same hevdar psykologspesialist Birgit Valla (7). Ho meiner at vi kan operere med ei kategorisering som er meir kontekstuell enn ICD-10 og DSM-5. Ho nemner kategoriar som negative livshendingar eller trauma, familiekonfliktar, utfordringar i skulesamanheng eller arbeid, med meir. Dette er ei type diagnostisering som omfattar meir enn symptoma, sjølv om ho også nyttar omgrep som til dømes stemmehøyring, sterk eller lammande uro og det å vere nedstemt. I hennar praksis vert desse kategoriane reviderte kvart år utifrå dei erfaringane dei gjer seg. Slik syner ho at det berre er snakk om språklege uttrykk for kategoriar som speglar fenomen i stadig endring.

\section{DIAGNOSANE GIR AUKA MEDISINBRUK}

Andre hevdar at mange av diagnosane fungerer sjukeleggjerande i det dei bryt ned distinksjonen mellom livsproblem og psykopatologi. Til dømes skil ikkje angst- og depresjonskriteria godt nok mellom alminneleg tristleik og alminneleg frykt med klinisk depresjon og angst. Forskjellen mellom mental dysfunksjon og livssituasjon kjem ikkje fram berre basert på symptoma. Risikoen er dermed ei individualisering av sosiale problem og ei 
innskrenking av høvet til å gjere noko med livsvilkåra.

Ein velkjent kritikk har vore at diagnosesystemet og dei som stod for utarbeidinga av dette, var for tett knytta opp mot legemiddelindustrien, og at dette har resultert i auka bruk av sjukeleggjering og medikalisering av livsproblem. (8)

\section{«Det gjør noe med selvfølelse og selvtillit når andre \\ ikke ser ens ressurser ...» «Victoria Ibabao Edwards»}

Ein annan kritikk er at diagnostisk tilnærming til psykiske helseutfordringar har opna for større grad av standardisering av behandlingstilnærmingane og redusert tilgangen til individuelt tilrettelagt behandling.

\section{DIAGNOSANE SIN FUNKSJON ER UKLAR}

Ifylgje Åsne Tveito skal diagnosane vere ei arbeidshypotese som skal drøftast med pasienten, og ikkje ei årsaksforklaring på lidinga (9). Deira viktigaste funksjon er å indikere retninga på behandlingsintervensjonane. Kritikken går mellom anna på at det ikkje eksisterer empirisk grunnlag for at det finst spesifikke terapiar for spesifikke lidingar trass i mange års forsking $i$ psykoterapi. Forskinga viser derimot at sjølve metoden er minst like viktig for at pasienten skal oppleve ei betring i sin livssituasjon (10-12). Konklusjonen frå denne forskinga er klar: Vi kan ikkje behandle psykiske lidingar, berre psykisk lidande menneske der relasjonen og den terapeutiske alliansen er det sentrale.

For å få utløyst økonomisk stønad frå NAV, må ein ha ei diagnose. Ein kritikk har vore at diagnosane såleis ikkje lenger berre er medisinske kategoriar, men også økonomiske kategoriar (jamfør innsatsstyrt finansiering) (13). I helsestatistikken er diagnosane nytta til dimensjonering av tiltak og vurdering av resultat. Prosedyrar for kvalitetssikring og såkalla evidensbasert praksis vert dokumentert med utgangspunkt i diagnosane.

\section{KVA GJER DET MED DEN EINSKILDE Å FÅ EIN DIAGNOSE?}

Mangfaldet når det gjeld opplevinga av å få ein psykiatrisk diagnose er like stort som menneska er forskjellige. For nokre kan ein diagnose gi håp, for andre det motsette. Nokre opplev at dei ikkje blir sett som den personen dei er, men berre som den merkelappen diagnosen representerer. Andre opplev at dei får ny identitet gjennom diagnosen. Ein fersk kvalitativ studie gjort av Monika Knudsen Gullslett (14), syner at brukarar føler seg vurderte, ikkje tatt på alvor, og møtt med mistru på grunn av at dei har ein diagnose. Dei fortalte at dei følte at apparatet snakka over hovudet på dei, og at dei ikkje vart inkluderte i samtalen.

Her vil eg kome med nokre uttaler frå brukarar, fyrst om det å få eller misse håp:

«Jeg fikk bare beskjed om å spise pillene han skreiv ut.» Ingunn, 24 år

«Lev et liv med bipolare utfordringer, den som vil prøve. Dette svingende livet representerer for meg et liv uten trygghet og med manglende forutsigbarhet. Velg et liv hvor du 'ser' meg ikke min diagnose. Du må bære mitt håp.» Connie Liv Straume (15)

«Å få diagnosen schizofren var én ting og ille nok. Enda verre var det å bli fortalt at dette er en kronisk lidelse som gjorde at jeg ikke kunne regne med å klare studiene eller ha en fast jobb. Jeg ble bedt om å legge alle planer til side.» Karl, 25 år

«Det var urettferdig å bli målt da jeg var på det nederste nivået i livet mitt. Det gjør noe med selvfølelse og selvtillit når andre ikke ser ens ressurser og ikke er interessert i ens drømmer. 


\section{DIAGNOSANE KAN GI OPPLEVING AV LETTE}

Andre uttaler handlar om at diagnosen kan avlaste frå skyldkjensle og ansvar, noko som kan ha både positive og negative verknadar. Fleire brukarstemmer har uttrykt at diagnosane langt frå styrka dei eller utfordra dei til å ta ansvar for å gjere endringar i tankemønster eller åtferd. Men i ei fase kan diagnosen avlaste og gi ei oppleving av lette.

«Jeg ble letta da legen sa at jeg hadde ADHD. Det ble liksom ikke min skyld at jeg var så urolig og hadde problemer med å konsentrere meg. Det er på grunn av sykdommen.» Beate, 34 år

«Det vart ei stor lette for meg då eg fekk vite at eg hadde OCD (obsessiv-kompulsiv lidelse). Eg forstod at eg ikkje var åleine om å ha slike ritual og tvangstankar. Eg blei den som hadde ei liding som andre også kjente igjen. Eg var ikkje så åleine, på ein måte.» Ole, 41 år

«Det gjør noe med selvfølelse og selvtillit når andre ikke ser ens ressurser ...» Victoria Ibabao Edwards

Diagnosane kan også vere med på å framandgjere pasienten og hindre at vedkomande kjem gjennom problema. Dermed kan dei bli større fordi ein ikkje tar tak i det som ligg bak symptoma.

«Jeg fikk en diagnose som het alvorlig depressiv episode uten psykotiske symptomer - uten at psykiateren forklarte meg hva det betydde. Jeg fikk bare beskjed om å spise pillene han skreiv ut. Jeg har forstått senere etter å ha snakka med ei god venninne, at grunnen til at jeg var så lei meg i den tida, hadde med bestemor å gjøre. Hun døde samtidig som jeg skulle ta eksamen, og hun betydde alt for meg. Jeg fikk liksom ikke tid til å gråte og sørge. Jeg bare jobba og leste og rømte fra alle følelsene mine inntil jeg traff veggen.» Ingunn, 24 år

\section{PÅ TIDE MED GRUNNLEGGANDE ENDRINGAR}

Det er motstridande erfaringar med diagnosane slik dei vert nytta i dag. God, gjentatt, nyansert, tilpassa informasjon og kunnskap om diagnosar kunne ha hindra mange mistydingar og stigma. Mange klinikarar meiner at diagnosane er hjelpsame både for å forstå pasienten sine problem og for å legge til rette tenestene. Også brukarar og brukarorganisasjonar, slik som til dømes ADHD-foreininga, er samde i dette. Andre klinikarar, brukarar og brukarorganisasjonar meiner at det er på tide å gjere grunnleggande endringar når det gjeld diagnosesystema slik vi nytter dei i dag.

Påstanden om at diagnosane ikkje har høg validitet, og at dei er sirkulære, er kunnskapsbasert. Det burde vere grunn nok til å sjå nærare på både innhald og korleis diagnosane vert nytta.

\section{TILRÅDING OM BRUKEN AV DIAGNOSAR}

Kva slags funksjonar skal så eit kategoriseringssystem ha? Etter mi meining er det viktigaste å få skilt mellom kliniske og administrative funksjonar og mellom livsproblem og psykiske lidingar. Det trengst dessutan tydelegare formidling om kva kategoriseringa av dei psykiske helseutfordringane skal vere til for. Målgruppene for denne informasjonen er både fagfolk, brukarar og ålmenta.

Nasjonalt senter for erfaringskompetanse innan psykisk helse sitt rådgivande utval, samansett av både forskarar, klinikarar og brukarar, har kome med si tilråding når det gjeld bruken av diagnosar (17). Dei tilrår at faktisk funksjonsnivå på dei viktigaste livsområda vert 
lagt til grunn for behandlingsstrategiar i større grad enn det vert gjort i dag. Kartlegginga av problemområde og utfordringar bør gjerast i samarbeid med pasienten og hans eller hennar nettverk og inkludere pasienten si historie og erfaringar. Diagnostikken skal berre vere eitt av fleire element i vurderingsgrunnlaget. Individuelle planar og behandlingsplanar slik vi kjenne dei i dag, bør supplerast eller erstattast av ein meir omfattande planprosess med pasienten i førarsetet. Og utvalet råder frå koblinga mellom bruk av diagnosar og retten til $\varnothing$ konomisk støtte og forsikringar. Det trengs andre metodar for å vurdere og sikre inntekt ved ulike funksjonstap.

\section{MERKSEMD PÅ PERSON, IKKJE SJUKDOM}

Dersom terapeutens utgangspunkt for behandling heretter skal vere spørsmålet: «Kva er viktig for deg, i staden for kva som er i vegen med deg?», må dette etter mi meining få konsekvensar for måten vi møter og forstår det pasienten treng hjelp til. Både ICD-10 og DSM-5 har store manglar, noko den nye manualen RDoC prøver å rette opp. Før vi eventuelt innfører endå eit nytt diagnosesystem, er det etter mi meining behov for ei opprydding når det gjeld kva slags funksjon og posisjon ein skal legge til diagnosane. Vi må skifte frå å fokusere på sjukdom og symptom til å rette merksemda på den situasjonen ein lever $\mathrm{i}, \mathrm{og}$ det ein har opplevd. Då må vi søke eit språk som inkluderer heile mennesket med sine sår og ressursar. Det nyttar ikkje å presse mennesket inn i ein diagnose eller eit manualbasert behandlingsopplegg.

\section{REFERANSAR}

1. Rognes W. Klassifikasjonssystemer og diagnostisk praksis. Diagnoser. Impuls 2003;1.

2. Kraft P. Motvind fra alle kanter. Tidsskrift for Norsk psykologforening.

2016;5:380-385.Tilgjengeleg frå: http://www.psykologtidsskriftet.no/index.php?seks_id=463364\&a=3

. (:Lasta ned 02.09.2016).

3. Ekeland TJ. Ny kunnskap - ny praksis. Et nytt psykisk helsevern. Nasjonalt senter for erfaringskompetanse; 2011:1.

4. Høye A. På tide å tenke nytt om psykiatriske diagnoser. Tidsskrift for Den norske legeforening. 2013;133:1329-31. Tilgjengeleg frå: http://tidsskriftet.no/article/3029122/. (Lasta ned 02.09.2016).

5. Brinkmann S, Petersen A (red.). Diagnoser. Perspektiver, kritik og diskussion. Aarhus: Klim, 2015.

6. Kinderman P. Fra sykeliggjort til aktiv deltaker - i stedet for dagens psykiatri. Oslo: Abstrakt forlag, 2016.

7. Valla B. Begynnelse på slutten for diagnosene. Tidsskrift for Norsk psykologforening, 2016;5:386-7. Tilgjengeleg frå: http://www.psykologtidsskriftet.no/index.php?seks_id=463430\&a=3 . (Lasta ned 02.09.2016).

8. Davies J. Sammenbrudd. Hvorfor psykiatri gjør meir skade enn gagn. Oslo: Abstrakt forlag, 2016.

9. Tveito Å. Hva skal vi med diagnosene? (Debatt). Tidsskrift for Norsk psykologforening, 2012;10:990-1008. Tilgjengeleg frå: http://www.psykologtidsskriftet.no/index.php?seks_id=276613\&a=4 . (Lasta ned 02.09.2016).

10. Borg, M. \& Topor, A. Virksomme relasjoner: Bedringsprosesser ved alvorlige psykiske 
11. Wampold BE. The Great psychotherapy debate: Models, methods, and findings. Mahway, NJ: Lawrence Erlbaum Associates, 2001.

12. Aarre T. Manifest for psykisk helsevern. Oslo: Universitetsforlaget, 2010.

13. Ekeland TJ. Ein diagnose av psykiatridiagnoser. Impuls 2003;1.

14. Gullslett MK. En kvalitativ studie om personlige opplevelser og erfaringer med psykiske kriser og hjelp fra et ambulant akutt-team - hva kan fremme bedring i psykiske kriser? (Doktoravhandling). Drammen: Høgskolen i Sør- $\varnothing$ st Norge, 2016.

15. Straume CL. Velg et liv - psykisk lidelse. Sinn og Samfunn, 2016;1:38.

16. Edwards VI. Redusert til en diagnose. (Nettintervju), 2013. Tilgjengeleg frå: http://www.erfaringskompetanse.no/nyheter/redusert-til-en-diagnose/. (Lasta ned 02.09.2016).

17. Nasjonalt senter for erfaringskompetanse: God behandling i et brukerperspektiv Anbefalinger fra rådgivende utval, 2015. Tilgjengeleg frå:

http://www.erfaringskompetanse.no/wp-content/uploads/2015/12/Anbefalinger-fra-rådgivende-utvalg.pdf . (Lasta ned 02.09.2016). 